\title{
A Case Study of Academics' Knowledge Sharing Motivations at Malaysian Public Academic Institutions
}

\author{
${ }^{*}$ Alsaleh Saad ${ }^{1}$, Haryani Haron² \\ ${ }^{1}$ Ministry of Health Hail, Saudi Arabia \\ 2University Technology Mara (UiTM), Malaysia \\ *captiansaadasa@yahoo.com
}

\begin{abstract}
This qualitative case study aims to explore and describe the academicians' knowledge sharing motivations in a Malaysian public university. A single case study was conducted with the aim to gather deeper insights on the knowledge sharing motivation. Data were collected through semi-structured interviews. A total of 15 renowned academicians were interviewed. Content analysis method was used to extract the knowledge sharing motivations from the qualitative data. The research results reveal seven important factors which motivate academicians to share their knowledge. These motivations are build reputation, acknowledgement (includes gain rewards, get a promotion, and recognition), to be knowledgeable, reciprocity, vision and mission, mentoring, personal beliefs (includes culture, sense of responsibility, and religion). The research comprehensive analysis and results would expand an area of knowledge sharing motivations among academicians in universities which may still theoretically and empirically not adequately explored and described.
\end{abstract}

Keywords: Knowledge Sharing; Knowledge Sharing Motivation; Academicians; Malaysian Public Higher Institutions

\section{Introduction}

Nowadays, there is a growing attention in treating knowledge as a vital resource for organizations. Increasingly, knowledge recognized as an important asset, particularly, in a modern organization (Bonifacio, Bouquet \& Cuel, 2002). The universities are knowledge intensive environments and it has played an important role in sharing knowledge (Fullwood, Rowley \& Delbrid, 2013). Several studies investigate and discussed the importance of the knowledge sharing. For instance, Jain, Sandhu, and Sidhu (2007) point out that the knowledge sharing is the most important matter should be considered within the knowledge management domain, hence, knowledge management effective strategies should emphasize the knowledge sharing role to maximize the benefit that could organization gain. In addition, the knowledge sharing is an important factor for organizations to be survived and succeed (Nonaka, 1995; Abdullah, Hamzah, Arshad \& Ghani, 2011; Abedini, 2012; Seonghee \& Boryung, 2008) includes academic institutions (Syed-Ikhsan \& Rowland 2004). The success could be represented in gaining a new advantages and improving performance. In several organizations, knowledge is an important because it enhances the quality of its workers (Gorry, 2008) as well as enhances the operational efficiency (Antonova, Csepregi \& Marchev, 2011). In an academic environment, particularly, in universities, sharing of knowledge is the most important component, because all staffs are often dealing with the knowledge (Trehan \& Kushwaha, 2012). According to Jain et al. (2007) "In an educational set up, effective knowledge sharing ensures that academics are able to realize and develop their potential to the fullest" (p.23). Meanwhile the sharing of knowledge is more critical in universities; the academicians' perceptions and willingness toward knowledge sharing are an important part of the knowledge management process (Abdullah et al., 2011). Although, the knowledge sharing is important and could generate numerous benefits, it is one of the main problems and challenges for the organizations (Antonova et al., 2011; Bock \& Kim, 2002; Haldin-Herrgard, 2000). The success of knowledge sharing efforts is almost depending on the individual willingness to share. Knowledge sharing behaviors can be promoted through motivating individuals to engage in such behaviors (Bock, Zmud, Kim \& Lee, 2005). Hence, this research aims to explore and describe in-depth, the most important factors that would motivate the academicians to share their knowledge in academic institutions. 


\section{Literature Review}

Knowledge Sharing Definition and Importance: Through reviewing many related literatures, it has been noted that there is no one or unique definition for the knowledge sharing. Even though that these definitions are concur about the main concept of knowledge sharing as an exchange of knowledge among individuals, several authors define knowledge sharing from their personal perspectives. For example, Alavi and Leidner (2001) define knowledge sharing as distribute knowledge throughout the organization. The distribution can occur between individuals, groups, or organizations using any kind of communication channels. Connelly and Kelloway (2003) define knowledge sharing as "A set of behaviors that involves of information or assistance to other" (p.294). Sveiby and Simons (2002) define knowledge sharing as share ideas and knowledge among individuals who have a common purpose and experience regardless of their locations. Similar to Sveiby \& Simons (2002) definition, Sharratt and Usoro (2003) define knowledge sharing as "A process whereby a resource is given by one party and received by another" (p.188). For the purpose of this research, knowledge sharing refers to a process where academicians mutually exchange their knowledge.

On the other hand, the knowledge sharing is essential and vital activity for most of the world organizations because of its role to generate valuable benefits as well as achieving success. Several studies have investigated and discuss the importance of the knowledge sharing. For instance, Nonaka (1995) suggests that for the organizations, to achieve success, they should consistently generate new knowledge, distribute it within the organization, and embody it in both new technologies and products. Yang (2007) stresses that the value of knowledge could be expanded if it is shared, hence, if managed properly, knowledge sharing can enhance the organizations in term of the quality of its work, decision making skills, the efficiency of problem solving, and competency. From an academic perspective, knowledge management practices have heavily involved in Higher Learning Institutions, particularly, universities, which make the sharing of knowledge in these institutions a popular debate (Cheng, Ho \& Lau, 2009). Sharing of knowledge in the universities is the most important component since all staffs are often dealing with the knowledge (Trehan \& Kushwaha, 2012). Martin and Marion (2005) point out that the academic institutions should serve as a platform to assist academicians to interact with each other and welcome their ideas and insights.

Factors Influencing Knowledge Sharing Behavior: Sharing knowledge leads to increase the performance and productivity among academician. Several studies have been conducted to find out the motivation factors that affecting an individual's knowledge sharing behavior. For example, Cheng et al. (2009) conduct a study in an academic institution to examine the behavior of knowledge sharing among academic staff. The findings of their study show that personal expectation and incentive systems are two significant motivation factors to knowledge sharing. Jain et al. (2007) and Seonghee \& Boryung (2008) found that reward is an important motivation factor for knowledge sharing. In his study, Luo (2009) examines the determinants of knowledge sharing in university academic team. He found that the extrinsic rewards and reciprocal relationships have a significant influence on academicians' intention to share knowledge. Supar (2006) conducts a study to discover factors that effect on knowledge sharing among academicians. The overall findings indicated that solidarity, the existence of information technology for knowledge sharing purposes and mentoring, support of management, include knowledge sharing in a work process, distributed model are positively related to knowledge sharing and performance. Likewise, Jain et al. (2007) examine the factors that affected on knowledge sharing activities among academic staff. The results indicated that the formal and informal lack activities to cultivate sharing of knowledge, lack of time, and lack of rewards and recognition were the strongest barriers. Zawawi et al. (2011) found that the most factors that influence knowledge sharing behavior are lack of incentive rewards and lack of Information Communication Technology respectively. Abdullah, Selama, Jaafar, Abdullah, and Sura (2008) conduct a study on seven public universities in Malaysia. One of their study recommendations is that an incentive reward should be established for knowledge sharing.

Other researchers point out the reciprocity important in knowledge sharing (Bock et al., 2005). In his study, Luo (2009) mentions that the reciprocal relationship assists to make a relaxed academic environment where knowledge can be shared with each other in an effective and efficient way. The mutual sharing also has been identified as one of the factors that could affect the knowledge sharing behavior. On the other hand, building a good reputation is an important factor to promote knowledge sharing. Some studies findings suggest that the improving of personal reputation considers an important motivation for individual to knowledge sharing and being active participation (Chennamaneni, 2007; Lakhani \& Eric, 2003). Wasko and Faraj (2005) suggest that the individuals will contribute their knowledge when they 
believe that it enhances their reputation. Finally, as Zhang, Pablos and Zhou (2013) encouraging the workers' knowledge sharing behavior is a significant issue in the knowledge management field. More specifically, there is a need to look for the academic staff views on the ways that can be followed to encourage knowledge sharing among them (Jain et al., 2007).

\section{Methodology}

The approach of this study was descriptive qualitative research. As the aim of this research is to comprehensively describe and build in depth understanding of academicians' knowledge sharing motivation, thus, a qualitative approach is most appropriate. "The key idea behind qualitative research is to learn about the problem or issue from participants and engage in the best practices to obtain that information" (Creswell, 2007, p. 47). In this study, the purposeful technique was used to determine the appropriate and productive research participants. In a qualitative research method, the purposeful is the main technique which enables the researcher to select the best suitable sample so as to answer questions of research (Marshall, 1996). In order to decrease the potentiality of research bias, a high level of integrity has been prepared and considered. For instance, all participants in this research were notified that their participation in this study is totally volunteer- based and they have a freedom to either accept or refuse the participation. Those who accept the participation, they had a choice to determine the place and time which appropriate for them to conduct the interview. The data were collected through fifteen academic staff at one public universities in Malaysia. It is very common that the size of the sample in qualitative research is small (Fossey, Harvey, McDermott \& Davidson, 2002; Ryan, Coughlan \& Cronin, 2007). This public university has been chosen for an important reason. This university is one of the largest universities in the country with nearly 480 academic programs (by coursework and research modes), as such, that would offer big opportunities for deeply identifying as well as recognizing the various knowledge sharing motivations that its academic staff really share for.

The data were collected from the participants over a six month period through conduct semi-structured face-to-face interviews. Throughout the collection of data and coding, other activities are considered. As an example, during the interview, the participants have been motivated to talk as well as elaborate more through probing questions based on their responses. The interview question developed based on an understanding of the research problem through both reviewing and examining related literatures. As Creswell (2007), the qualitative researcher does not use or heavily rely on research questions which have been developed by other researchers. The interviews continued with the participants until they no provide or introduce new or different information and the data saturation developed in the answers. Reaching to the saturation stage determines the theoretical point at which a sufficient data have been gathered, hence, the adequate number of participants should be included (Jennings, 2011). Thirteen of the participants having a Professor positions', three of them are faculty deans and two having an Associate Professor position'. Two more participants were removed since they did not contribute enough and informative information as expected as a result of their limited time. The participants work in several faculties as well as disciplines. Even though they work in various faculties, the conclusion is that they have been a homogeneous participants since all of them were academicians and there was no any nonacademic staff engaged. Maxwell (1992) suggests that when implementing a qualitative research, the researchers should consider the validity of their finding. To ensure this research results validity, strategies were used in a credible scholarly. Johnson (1997) suggests strategies to promote qualitative research validity. In this research, two of these strategies have been used which are the Low Inference Description and Data Triangulation. Table 1 illustrates these strategies.

\section{Table 1: Qualitative Research Validity Strategies}

\begin{tabular}{lll}
\hline No & Strategy & Description \\
\hline 1 & Low Inference & The use of Description phrased very closed to the participants' accounts \\
& Description & $\begin{array}{l}\text { and researchers' field notes. Verbatim (i.e. Direct quotations) is a } \\
\text { commonly used type of low inference descriptor. }\end{array}$
\end{tabular}

2 Data triangulation The use of multiply data sources to help understand a phenomenon.

In this study, the Low Inference Description was tested through present direct quotations from the participants' responses. Johnson (1997) describes that "A verbatim is the lowest inference descriptor of all because the participants' exact words are provided in direct quotation" (p.285). In addition, Creswell (2007) point out that in qualitative research, the researchers bring in the voice of participants in the study 
like use sufficient quotes. The Data Triangulation was used in this study through conducting a multiinterview in different places and times have been done. Johnson (1997) mentions that "another important part of data triangulation involving collecting data at different times, at different places, and with different people" (p. 289).

\section{Results and Data Analysis}

Data Analysis: As a qualitative research, the second step was taken after gathering the data is an open coding and analysis of the participants' responses to the research questions. In the coding process, the interviews taped data were transcribed into written format then reviewed several times to interpret and determine the name as well as the main concepts of the motivation factors. To do so, the analyzing and coding of responses was line-by-line and the key concepts were identified through free coding. The researchers in qualitative research are engaged in understanding and interpreting the information. Creswell (2007) states that, in the qualitative research, the researcher "review all of the data and make sense of it, organizing it into categories or themes" (p.45). "Code labels emerge from several sources. They might be... drawn from names the researcher composes that seem to best describe the information" (Creswell, 2007, p.185).

Research Findings: The question that was prompt to the academicians was why they share their knowledge. In other words, what motivates them to share knowledge? The research found seven important factors which motivate academicians to share their knowledge. These factors are build reputation, acknowledgement (gain rewards, get a promotion, recognition), to be knowledgeable, reciprocity, vision and mission, mentoring, personal beliefs (include culture, sense of responsibility, and religion). The remainder of this section illustrates participants' responses which indicate these motivations. Firstly, building a good reputation is an important factor to academicians to share their knowledge. When he was asked why do you share your knowledge, participant 5, a professor in Chemical engineering, states that "When we have the knowledge, people will know you experts in the area for example the environment people will know you, people will know your university". Participant 9 also shared this same motivation when he requested to introduce his reasons for sharing of his knowledge with others; he mentions that "Because the important thing, by producing excellent academic students, means definitely we can bring up directly to the faculty and indirectly to the university. It has brought up an image; it is brought up the ranking of the university". Participant 1 express that "I share my knowledge to build reputation".

Secondly, receiving acknowledgement is motivating academicians to share their knowledge. Participant 1 adds that "I share my knowledge also to receive recognitions and gain award". Similarly, in her answer to, participant 2 mentions that "Many things motivate me to share knowledge like grant or reward, receiving acknowledgement". Participant 9 explains that one thing receiving acknowledgement would motivate him to share more. He had this to say "The acknowledgement so can put it in our CV [Curriculum Vitae], that we are appointed as external examiners that are another way why we do want to share with them". Participant 12 explains why he shares knowledge, and he argues that people share their knowledge only when others recognize it. He describes "You get a recognition from the university; you have a student who respects your knowledge. A person only shares their knowledge if it is recognized. I did that because it is recognized, but I do not share everything, because if they do not recognize it, even in a meeting at this university, because my idea, my knowledge in something and if they did not want to say about it, I will keep it to myself. Because, I only say something when they recognize, they welcome it, otherwise, I would not".

Participant 14 specifies how receiving recognition from another is important to him. He explains that "And the same time you wish that people would appreciate your work and so on ... being appreciated by other people". Participant 4 indicates that the acknowledgements whether monetary and non-monetary monetary still matter. She explains "Acknowledgements whether monetary and non-monetary still matter, research grant, the promotion. Then non-monetary the recognition matter like praise". Participant 12 mentions that one of the methods to confirm his position and get more academic promotions is through sharing of knowledge. He explains it this way "I need to share my knowledge in the way that I mentioned to you to get confirmed, to confirm my position. And then of course, the next stage will be to get myself promoted from junior to a lecturer and then to a senior lecturer and then to associate professor and the last one of course professor... in university, you are welcome to share your knowledge, because you get something, for example, you get confirmation, you get promotion". 
Thirdly, to be acknowledgeable also found an important motivation for academicians to share and contribute their knowledge. Some participants indicate that they share their knowledge with others to increase their own knowledge as a result of their sharing. When he asked why he shares the knowledge, participant 3 states "the more you share, the more you get, so I want to get more and more knowledge". Participant 8 shares same insight, he describes "There is one ethics or philosophy you can say, in this world, there is only one thing if you spend it is extended which is knowledge. That is why I share knowledge. This is [the] attitude of the human being. The human being does not want to be nonknowledgeable. Intention to learn". Participants 5 echo this view, he explains "at the same time you know share knowledge it will enhance your knowledge, increase your knowledge. And then if you do not know about the subject matter, you will see it how that you can get the knowledge from many sources internet, book and so on. If someone asks me, I got to study, I have to go [the] library. So when we give knowledge, knowledge will increase". Participant 4 explains that as part of knowledge sharing, sometimes we learn more from another person, since there are many things that you need to learn, hence, it is good to share knowledge when you need to know another point of view. Also, participant 11 share same notions, she explains "Because when you share your knowledge you learn as well. Is not a one way, when you share when you give you yourself gaining more? By sharing and by teaching others you learn more. Because knowledge is, what we have is so little, what we have is so little, there are so much more to learn. Because of that you must always make an effort to learn, and one way of learning is by sharing with others.

Participant 12 also continues this thought and he brought up an interesting matter related to wisdom as a result of a knowledge sharing. He describes "If you have one knowledge you give it to others, then the knowledge will increase. Because the ultimate things that you want to achieve in life is to become a man with wisdom. Wisdom not so many people have even leaders in the organization, they do not have, that is why they have wrong decisions". Besides, participant 10, a professor and former dean, explains that she shares and diffuses her knowledge because she needs to learn and be knowledgeable. She describes her points of view by "So in my case I think, I am not good enough, I still have to learn and learn and learn to be really good at it... I want to be good at certain things".

Fourthly, it has been found that the participants share their knowledge also because of mutual sharing benefits (reciprocity). For instance, participant 9 shares his knowledge to get feedback from who share with about his works. He explains "I share to get feedback to see whether the feedback is positive or negative and how we can correct it, how we can improve it, to hear their views on whatever we share to them, and maybe they have better other views, and maybe our views is not right, the knowledge that we got is maybe not to what is being expected. So from there we have got something maybe the same ideas, so we achieve something at the end of the day". In her answer, participant 6 notes that "We need each other. The interrelation there looks like need each other". Participant 12 believes that if the individuals benefit and help others through sharing of knowledge, they are benefiting and helping themselves as well. He explains "I share if it is beneficial, meaning that the knowledge can help the organization, the group the faculty, because in helping others you are helping yourself". Participant 14 describes how he makes a relationship network with other academicians to encourage them to share with him. He points out that "Being an academician you have to develop your networking, so one way of building your networking is by sharing. For example, if you want be academician you have to collaboration, you want to have some new ideas, comments on your work and the same time you wish that people would appreciate your work and so on. I mean you have to set up the networking, else you will be alone... you cannot be alone you have to share". Therefore, the fourth motivation that has been identified in this research is a reciprocity or the benefit from the mutual sharing of knowledge.

Fifthly, other participants share their knowledge because that they have and follow a vision and mission. For example, participant 9 describes how present of vision and mission encourage him to share knowledge not solely at the local level but also globally. He says "The vision and mission of the faculty. As a dean that motivate me to bring up the faculty to a higher level, we are talking about vision and mission we have strategic planning we strategize what are going to do, how going to improve, how do you want to move the faculty to a higher level, to be known not only national level but international level". Sixthly, the research found that respondent shares their knowledge because they want to be a mentor. For instance, participant 7 describes how to be a mentor on some of colleagues motivates her to share. She describes "We have a mentor-mentee system that is good. If anybody having that must do it. When there is a mentor-mentee, you become a mentor that is one nice already. You can mentor someone and the mentee is a junior and of course the mentee will be more in the same line with you. That kind of the junior that can do something as and you are the mentor, I feel good". So, the sixth motivation that motivates 
academicians to share their knowledge was being a mentor. Seventhly, the academicians personal beliefs (include culture, sense of responsibility, and religion) were founded as a motivation. Some participants mention that their culture motivated them to share their expertise and knowledge with other people. For example, participant 13 mentions that he shares his knowledge because it is a Malay culture. He points out that "This is [a] Malay. Malay we have the concept that if you help people, people will help you back. Because I would say, our culture meaning you should help people and then one day people will help you back". In the same motivation line, participant 4 indicates the influence of culture to share knowledge. She states that "So, I guess that is another motivation at the moment [which is] the culture of higher institution now [is] different. Yes, it is different; it is not like ten years ago".

Other academicians believe that it is their duty and responsibility to share their knowledge with others. For instance, participant 7, a dean of faculty, share his knowledge with others because he believes that he has to share, there is no other choice. He states that "It is not why; I have to share because I have been here administrator. I [have] experience [most?] of the senior members of the faculty, I have to develop the faculty, I have to share with them my experience and my knowledge so that develop the faculty and develop them, develop the personal and also develop the faculty. I think [that] it [is] my obligation to make sure the profession develop and advance". In same insights, participant 11 shares her knowledge because she believes that it is her responsibility to share and also she thinks that the knowledge will be usefulness if it is not shared to benefit another. She felt that she has to share; otherwise it does not to be benefited to any humankind. Because whenever she felt that her sharing of knowledge will benefit the other party or the people she will share without any hesitate. She continues describing her feeling by saying that "Knowledge is not useful if it does not benefit other people. I think it is more of what is right what should be done, is the responsibility, it is my responsibility to share with others". Participant 15 shares the same feeling. She felts that "Because I just feel like right doing so, I think it is a responsibility, it is an Amanah [Honesty], whatever the knowledge you get it is Amanah. I think it is part of my responsibility as an individual. It comes from my heart; I think it is my responsibility to educate the people that are the reason". Participant 13 is a professor of Construction Management, describes how the sharing of his knowledge with other people makes him happy due to his believing about what he called Iklas [dedication]. He expresses "If I can help them that makes me happy. I am happy because I help people. When you see people are happy you also happy.

This is about Iklas when doing something that because you think it is a good thing. You should help people. What is life if just for yourself"? The religion also as one of the participants believes part has been identified as an important motivation for academicians to share their knowledge. It was very clear from the participants' responses that their motivation to share knowledge is their religion beliefs as they believe that their religion encourage them to share what they know with others. For instance, when participant 3 has been asked why do you share your knowledge he states that "Prophet Mohammad peace be upon him encourage us to share with others and distribute the knowledge". Participant 4 shares her knowledge because she believes that ALLAH will reward her in another way. She expresses "I always believe that if we do something good to others, Allah will give us return in many other ways that we may or may not realize them. Allah gives me many advantages and strengths that others might not have yet. And whenever possible, I should share or help others with that". Participant 10 explains one more motivation to share her knowledge; she notes that "I want to be good at certain things. At least people who remember me, ALLAH say I am done good for the Aumah [Nation]".

Participant 13 has the same belief. Many religion phrases he was mentions which indicated his motivation to share his knowledge with others without exception. He describes that "ALLAH [Almighty] not losing anything, you I am not losing anything's. Religion verses of [the Holey] Quran. Similarly, participant 14 mentions that he shares knowledge because there is Hadith and a verse from the Holey Quran asks us to share knowledge. He states that you know the Hadith prophet Mohammad peace is upon him, you have one Hadith (Share your knowledge even one verse). Participant 5 indicates that "ALLAH will give us bless her after... because you know the Islam scholar they are good in many areas". Thus, the seventh and last motivation factor which has identified in this research is the Personal beliefs. Figure 1 illustrates academicians' knowledge sharing motivations.

Findings and Discussion: The multiple efforts of data analyses have been conducted to ensure thematic categories were accurate. Many research articles were reviewed with the aim of understanding of qualitative findings. The purpose of this study is to explore and describe the academicians' knowledge sharing motivation in academic institutions. The results of interviews reveal some important factors that 
would motivate the academicians to share their knowledge. The importance of these factors was different from academicians to another. There were nine motivation factors which are build reputation, acknowledgement (includes gain rewards, get a promotion, and recognition), personal beliefs (include culture, sense of responsibility, and religion), to be knowledgeable (to learn), reciprocity 9mutual sharing), present of vision and mission, and to be a mentor. The rest of this section discusses the motivation finding and relate it to other literatures. Building a good reputation in this study found to be as an important motivation for academicians to share knowledge. This results consistent with some previous studies which suggest that the reputation consider important motivational factors for knowledge sharing. For instance, research findings conduct by Chennamaneni (2007) provides evidence that reputation building is a reliable motivator for active participation. Wasko and Faraj (2005) study finding reveals that people contribute their own knowledge when they believe that contribution improves their professional reputation. Constant, Sproull, and Kiesler (1996) mention that one important motivation for offering useful advice to others is improve personal reputation. Emelo (2012) suggests that to help individuals share their knowledge and ideas, the reputation should consider as part of the intrinsic value. Drula (2009) points out that building a good reputation and sense of efficacy is an end in itself for some individuals to share knowledge.

Figure 1: Academicians' Knowledge Sharing Motivations

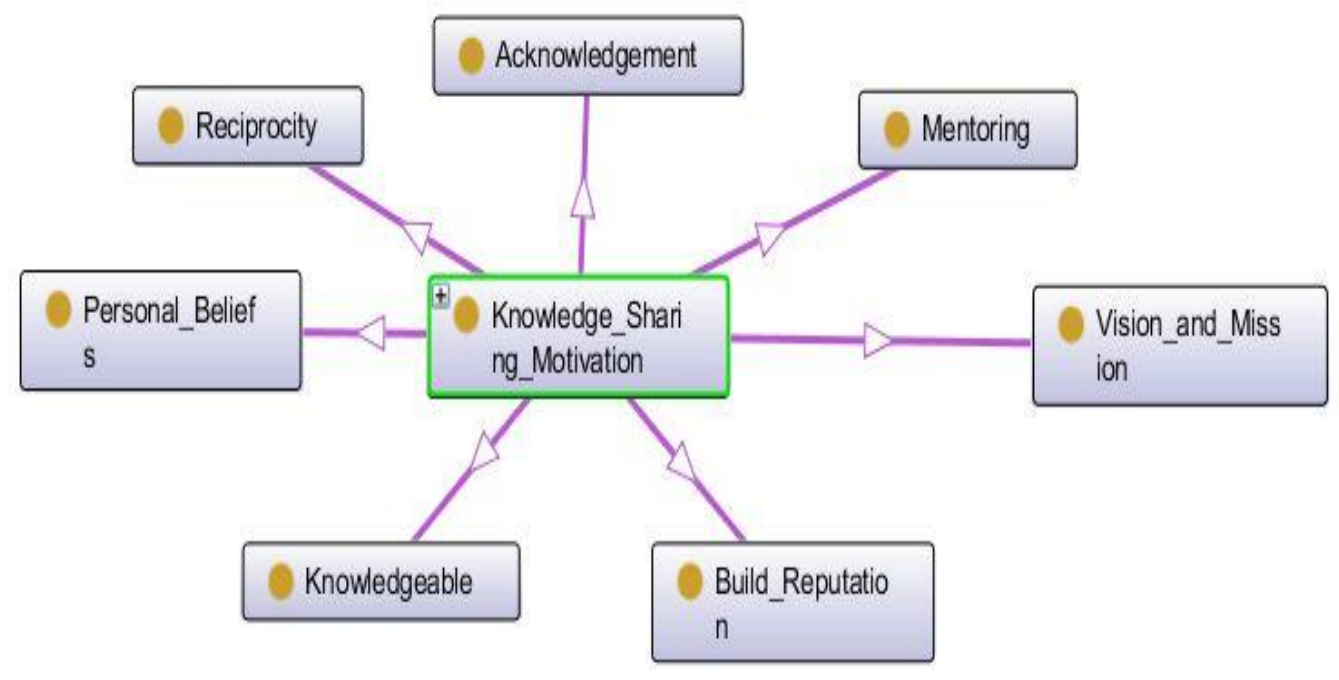

On the other hand, the research results reveal that the acknowledgement (both monetary and nonmonetary) surfaced as a positive motivate academician to share their knowledge. On other words, the results suggest that receiving acknowledge in return for sharing of knowledge will increase knowledge sharing among academicians. This finding accords with other recent research in the same environment. For instance, Abdullah et al. (2008) conduct a study in some Malaysia universities. Based on their study finding, they recommend offering an appropriate incentives as a mode of motivation for those who share their knowledge. Jain et al. (2007) examine the factors that affected on knowledge sharing activities among academic staff in Malaysia. They found a strong case for relating sharing of knowledge activity with rewards and appraisal of performance. Seonghee \& Boryung (2008) study reveals that the second most influential factor for sharing of knowledge in faculty is reward systems. Yue, Menkhoff, Loh, and Evers (2007) conduct study in Singapore academic institutions. The study findings indicate that incentives and rewards are one of the strongest knowledge sharing predictors. According to Cheng et al. (2009) the quality and amount of knowledge sharing are mostly depending on the incentive system both monetary and non-monetary. Numerous organizations allocate rewards for their employees for only sharing of knowledge (Peariasamy, Mansor, \& Naha, 2008). Muller, Spiliopoulou, Lenz (2005) explain the aim of an incentive system in organizations as it to affect on the individual behavior. Thus, universities should provide motivational incentives to encourage academicians to share their knowledge (Antonova et al., 2011).

On the other hand, the reciprocity has been found in this research as an important motivation factor for academicians to share their knowledge. Reciprocity is "knowledge exchanges that are mutual and 
perceived by the parties as fair" (Chiu, Hsu \& Wang, 2006, p.1877). This study finding is consist with several prior research results (Bock et al., 2005; Chennamaneni, 2007; Chiu et al., 2006; Kankanhalli, Tan \& Wei, 2005). Sun et al. (2009) conduct a research to identify the factors that may affect on individual intentions to share their knowledge. Their research findings show that people are willing to share knowledge if they consider some factors including reciprocity. Luo (2009) argues that the reciprocal relationship assist to build a friendly academic environment where knowledge can be shared with each other in an effective and efficient manner. Further, the research results reveal other motivational factors that influence academicians knowledge sharing behavior include present of vision and mission, personal beliefs, and become a mentor, as well as to be a knowledgeable.

\section{Conclusion and Future Work Recommendations}

This study identified seven important factors which motivate academicians in public university to share their knowledge. These factors are build reputation, acknowledgement (include gain rewards, get a promotion, recognition), to be knowledgeable, reciprocity, vision and mission, mentoring, personal beliefs (include culture, sense of responsibility, and religion). This research extends prior research on academic staff knowledge sharing motivations in higher learning institutions, particularly, public universities. The study findings might provide useful insights for the administrations of universities to exploit and employed these important factors in order to encourage their academic staff to share their knowledge, and as a result, enhance their performance. It is hopefully also this research contribute to current and future research on knowledge sharing motivations in the academic institutions. As this research focus on the solely knowledge sharing motivations among academicians in academic institutions, it is recommended to study the knowledge sharing motivation for the non-academic staff in the academic institutions.

Acknowledgement: The authors of this research paper introduce their thankfulness to the Saudi Ministry of Higher Education since it's under its scholarship and funding.

\section{References}

Abdullah, N. L., Hamzah, N., Arshad, R., Isa, R. M. \& Ghani, R. A. (2011). Psychological contract and knowledge sharing among academicians: mediating role of relational social capital. International Business Research, 4(4), 231.

Abdullah, R., Selamat, M. H., Jaafar, A., Abdullah, S. \& Sura, S. (2008). An Empirical Study of Knowledge Management System Implementation in Public Higher Learning Institution.

Abedini, A. (2012). An analysis of factors affecting staffs knowledge sharing in the central library of the University of Isfahan using the extension of Theory of Reasoned Action. International Journal of Human Resource Studies, 2(1), 158.

Alavi, M. \& Leidner, D. E. (2001). Review: Knowledge management and knowledge management systems: Conceptual foundations and research issues. MIS quarterly, 2, 107-136.

Antonova, A., Csepregi, A. \& Marchev-Jr, A. (2011). How to extend the ICT used at organizations for transferring and sharing knowledge. Available at SSRN 1776642.

Bock, G. W. \& Kim, Y. G. (2002). Breaking the myths of rewards: an exploratory study of attitudes about knowledge sharing. Information Resources Management Journal (IRMJ), 15(2), 14-21.

Bock, G. W., Zmud, R. W., Kim, Y. G. \& Lee, J. N. (2005). Behavioral intention formation in knowledge sharing: Examining the roles of extrinsic motivators, social-psychological forces, and organizational climate. MIS quarterly, 2, 87-111.

Bonifacio, M., Bouquet, P. \& Cuel, R. (2002). The role of classification (s) in distributed knowledge management. In Proc. of KES (2).

Cheng, M. Y., Ho, J. S. Y. \& Lau, P. M. (2009). Knowledge sharing in academic institutions: a study of Multimedia University Malaysia. Electronic Journal of Knowledge Management, 7(3), 313-324.

Chennamaneni, A. (2007). Determinants of knowledge sharing behaviors: developing and testing an integrated theoretical model.

Chiu, C. M., Hsu, M. H. \& Wang, E. T. (2006). Understanding knowledge sharing in virtual communities: an integration of social capital and social cognitive theories. Decision support systems, 42(3), 18721888.

Connelly, C. E. \& Kelloway, E. K. (2003). Predictors of employees' perceptions of knowledge sharing cultures. 
Constant, D., Sproull, L. \& Kiesler, S. (1996). The kindness of strangers: The usefulness of electronic weak ties for technical advice. Organization science, 7(2), 119-135. Leadership \& Organization Development Journal, 24(5), 294-301.

Creswell, J. W. (2007). Qualitative Inquiry and Research Design: Choosing Among Five Approaches. SAGE Publications.

Drula, G. (2009). Sharing Knowledge Inside Social Network Sites. ET Scientia International Journal (LESIJ), (16-2), 463-473.

Emelo, R. (2012). Why personal reputation matters in virtual knowledge sharing. Industrial and Commercial Training, 44(1), 35-40.

Fossey, E., Harvey, C., McDermott, F. \& Davidson, L. (2002). Understanding and evaluating qualitative research. Australian and New Zealand journal of psychiatry, 36(6), 717-732.

Fullwood, R., Rowley, J. \& Delbridge, R. (2013). Knowledge sharing amongst academics in UK universities. Journal of Knowledge Management, 17(1), 123-136.

Gorry, G. A. (2008). Sharing knowledge in the public sector: two case studies. Knowledge Management Research \& Practice, 6(2), 105-111.

Haldin-Herrgard, T. (2000). Difficulties in diffusion of tacit knowledge in organizations. Journal of Intellectual capital, 1(4), 357-365.

Jain, K. K., Sandhu, M. S. \& Sidhu, G. K. (2007). Knowledge sharing among academic staff: A case study of business schools in Klang Valley, Malaysia. JASA, 2, 23-9.

Jennings, B. J. (2011). Factors that contribute to knowledge sharing within research based organizations. (Order No. 3473197, The University of New Mexico). ProQuest Dissertations and Theses, , 219.

Johnson, R. B. (1997). Examining the validity structure of qualitative research. Education, 118(2), 282292.

Kankanhalli, A., Tan, B. C. \& Wei, K. K. (2005). Contributing knowledge to electronic knowledge repositories: an empirical investigation. Mis Quarterly, 3, 113-143.

Lakhani, K. R. \& Eric, V. H. (2003). How open source software works: "free" user-to-user assistance. Research policy, 32(6), 923-943.

Luo, H. (2009). Determinants of knowledge sharing in university academic team. In Knowledge Acquisition and Modeling. KAM'09. Second International Symposium on IEEE, 1, 260-263.

Marshall, M. N. (1996). Sampling for qualitative research. Family practice, 13(6), 522-526.

Martin, J. S. \& Marion, R. (2005). Higher education leadership roles in knowledge processing. Learning Organization, 12(2), 140-151.

Maxwell, J. A. (1992). Understanding and validity in qualitative research. Harvard educational review, 62(3), 279-301. ISO 690.

Muller, R. M., Spiliopoulou, M. \& Lenz, H. J. (2005). The influence of incentives and culture on knowledge sharing. In System Sciences, 2005. HICSS'05. Proceedings of the 38th Annual Hawaii International Conference on (pp. 247b-247b). IEEE.

Nonaka, I. (1995). The Knowledge-Creating Company: How Japanese Companies Create the Dynamics of Innovation: How Japanese Companies Create the Dynamics of Innovation. Oxford university press.

Peariasamy, T., Mansor, A. \& Naha, N. (2008). On-the job knowledge sharing: how to train employees to share job knowledge. Jurnal Kemanusiaan, 12, 87-101.

Ryan, F., Coughlan, M. \& Cronin, P. (2007). Step-by-step guide to critiquing research. Part 2: qualitative research. British Journal of Nursing, 16(12), 738-744.

Seonghee, K. \& Boryung, J. (2008). An analysis of faculty perceptions: Attitudes toward knowledge sharing and collaboration in an academic institution. Library \& Information Science Research, 30(4), 282290

Sharratt, M. \& Usoro, A. (2003). Understanding knowledge-sharing in online communities of practice. Electronic Journal on Knowledge Management, 1(2), 187-196.

Sun, S. Y., Ju, T. L., Chumg, H. F., Wu, C. Y. \& Chao, P. J. (2009). Influence on Willingness of Virtual Community's Knowledge Sharing: Based on Social Capital Theory and Habitual Domain. World Academy of Science, Engineering and Technology, 53, 142-149.

Supar, N. (2006). Factors Affecting Knowledge Sharing Among Academic Staff in Selected Malaysian Higher Educational Institutions and the Effect on Performance. (Doctoral dissertation, Universiti Putra Malaysia) Retrived from psasir. 5583

Sveiby, E. \& Simons, R. (2002). Collaborative climate and effectiveness of knowledge work-an empirical study. Journal of Knowledge Management, 6(5), 420-433.

Syed-Ikhsan, S. O. S. \& Rowland, F. (2004). Benchmarking knowledge management in a public organisation in Malaysia. Benchmarking: An International Journal, 11(3), 238-266. 
Trehan, A. \& Kushwaha, P. (2012). The implementation of Knowledge Management System in B-Schools. International Journal of Multidisciplinary Management Studies, 2(2).

Wasko, M. M. \& Faraj, S. (2005). Why should I share? Examining social capital and knowledge contribution in electronic networks of practice. MIS quarterly, 3, 35-57.

Yang, J. T. (2007). The impact of knowledge sharing on organizational learning and effectiveness. Journal of Knowledge Management, 11(2), 83-90.

Yue Wah, C., Menkhoff, T., Loh, B. \& Evers, H. D. (2007). Social capital and knowledge sharing in knowledge-based organizations: An empirical study. International Journal of Knowledge Management (IJKM), 3(1), 29-48.

Zawawi, A. A., Zakaria, Z., Kamarunzaman, N. Z., Noordin, N., Sawal, M. Z. H. M., Junos, N. M. \& Najid, N. S. A. N. (2011). The Study of Barrier Factors in Knowledge Sharing: A Case Study in Public University. Management Science and Engineering, 5(1), 59-70.

Zhang, X., Pablos, P. O. D. \& Zhou, Z. (2013). Effect of knowledge sharing visibility on incentive-based relationship in Electronic Knowledge Management Systems: An empirical investigation. Computers in Human Behavior, 29(2), 307-313. 